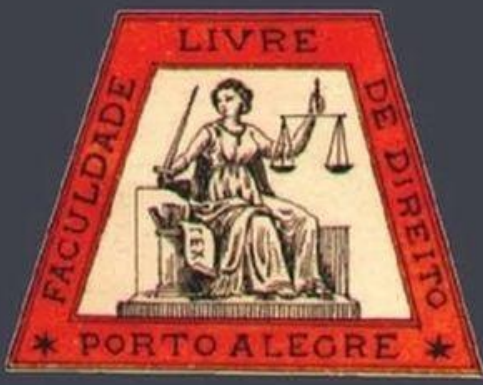

\title{
A tradição constitucionalista e sua importância para a consolidação de um regime democrático
}

The constitutionalist tradition and its importance for the consolidation of a democratic regime

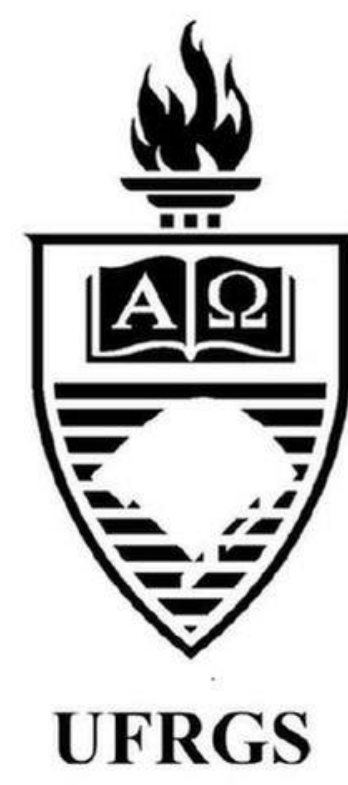

Fábio Marques Gonçalves Universidade Estadual Paulista "Júlio de Mesquita Filho"

\section{Danilo Pereira Lima}

Universidade do Vale do Rio dos Sinos 


\title{
A tradição constitucionalista e sua importância para a consolidação de um regime democrático
}

\author{
For a public policy for access to juvenile restorative justice: beyond the Judiciary
}

Fábio Marques Gonçalves*

Danilo Pereira Lima**

\section{REFERÊNCIA}

GONÇALVES, Fábio Marques; LIMA, Danilo Pereira. A tradição constitucionalista e sua importância para a consolidação de um regime democrático. Revista da Faculdade de Direito da UFRGS, Porto Alegre, n. 40, p. 116-130, ago. 2019.

\section{RESUMO}

O presente artigo tem o objetivo de descrever brevemente a história do constitucionalismo moderno, passando pelos contextos históricos em que se insere essa tradição e fazendo uma análise de seu legado, construído em cada etapa de desenvolvimento do Estado moderno - Liberal, Social e Democrático. Busca-se também uma análise da realidade brasileira, fazendo-se um recorte a partir de 1988, quando surge a Constituição Democrática. Esse momento é importante para a reflexão sobre o contraste entre abertura democrática e inconstitucionalidades que se apresentam na realidade do país, devidas, em grande medida, à não superação de todos os resquícios do autoritarismo de seu passado histórico. Também se apresenta o exemplo da atuação dos meios de comunicação brasileiros, que ilustra, de forma clara, a situação de ausência de respeito à Constituição da República. Essas análises serão desenvolvidas sob o marco da Crítica Hermenêutica do Direito, de Lenio Streck. A partir desse aporte teórico, o artigo aponta para a necessidade de se fortalecer anteparos jurídicos contra qualquer manifestação personalista do poder, de modo a impedir que o direito seja solapado pela vontade dos agentes políticos. Adota-se, como técnica de pesquisa, a revisão bibliográfica e busca-se o desenvolvimento metodológico do trabalho a partir da construção de um quadro referencial teórico coerente e integrado à historicidade.

\section{PALAVRAS-CHAVE}

Direito Constitucional. Constitucionalismo. Estado moderno. Democracia. Crítica Hermenêutica do Direito.

\section{ABSTRACT}

The present article aims to briefly describe the history of modern constitutionalism, considering the historical contexts in which this tradition is inserted and analyzing its legacy, built at each stage of development of the modern State - Liberal, Social and Democratic. An analysis of Brazilian reality is also sought, making a cut from 1988, when the Democratic Constitution arises. This moment is important for the reflection on the contrast between democratic opening and unconstitutionalities that present themselves in the reality of the country, due to, largely, not overcoming all the remnants of authoritarianism of its history. The example of the Brazilian media is also presented, which clearly illustrates the lack of respect for the Constitution of the Republic. These analyzes will be developed under the framework of the Critical Hermeneutics of Law, by Lenio Streck. Based on this theoretical contribution, the article points to the need to strengthen legal frameworks against any manifestation of personal power, to prevent Law from being undermined by the will of political agents. The bibliographical review is adopted as research technique, and the methodological development of the work is sought from the construction of a coherent theoretical framework, integrated with historicity.

\section{KEYWORDS}

Constitutional law. Constitutionalism. Modern State. Democracy. Crítica Hermenêutica do Direito.

\footnotetext{
* Mestrando em Direito pela Faculdade de Ciências Humanas e Sociais da Universidade Estadual Paulista "Júlio de Mesquita Filho" (FCHS-UNESP), Franca (SP) (Departamento de Direito Público - Direito Constitucional e Teoria do Estado).

${ }^{* * *}$ Doutor em Direito Público pela Universidade do Vale do Rio dos Sinos (RS). Membro do Grupo "Dasein - Núcleo de Estudos Hermenêuticos" (Unisinos). Professor de Ciência Política e Teoria Geral do Estado.
} 


\section{SUMÁRIO}

Introdução. 1. Um breve retrospecto sobre o conceito de constitucionalismo. 2. A democracia pós-autoritária brasileira e o apequenamento da ideia de normatividade constitucional. Conclusão. Referências.

\section{INTRODUÇÃO}

O presente trabalho faz uma breve reconstrução histórica da tradição constitucionalista que surge na modernidade, bem como uma reflexão sobre sua importância para a consolidação das democracias do século XXI, especialmente aquelas que foram antecedidas por períodos de autoritarismo e suspensão das liberdades fundamentais. Retomar os sentidos dessa tradição se faz necessário para a reflexão sobre as condições de possibilidade para a democracia na contemporaneidade.

A limitação do poder político sempre foi um grande desafio para o constitucionalismo. Sem dúvida alguma, a elaboração de mecanismos jurídicos, voltados para impedir a formação de regimes arbitrários, foi fundamental para que o direito se sobrepusesse à política e garantisse melhores condições institucionais para o estabelecimento do regime democrático. Diante da ausência de qualquer limite constitucional, um monarca ou um presidente da República podem governar de maneira autoritária; o Legislativo, por meio da maioria parlamentar, pode atropelar as minorias e fazer com que predomine um regime despótico; e os juízes, através da discricionariedade, podem ignorar o direito e decidir com argumentos de política, conforme suas preferências pessoais. Assim, somente um regime político que se submeta ao Estado de Direito tem condições institucionais para fazer com que os princípios democráticos sejam devidamente respeitados.

Para que o direito conquistasse o seu status de autonomia em relação à política, à moral e à economia foi preciso percorrer um longo caminho. Diversas guerras e revoluções tiveram que acontecer para que o constitucionalismo elaborasse seus próprios mecanismos de limitação do poder político. $\mathrm{O}$ desafio de fazer com que um regime político, fundamentado no direito, não fosse dizimado por um poder arbitrário sempre foi o grande objetivo do constitucionalismo.

As reflexões deste artigo serão desenvolvidas sob o marco da Crítica Hermenêutica do Direito, de Lenio Streck (2013). A partir desse aporte teórico, o artigo aponta para a necessidade de se fortalecer anteparos jurídicos contra qualquer manifestação personalista do poder, de modo a impedir que o direito seja solapado pela vontade dos agentes políticos.

Assim, na primeira parte do trabalho serão abordadas as condições nas quais surge a primeira modernidade europeia, com sua dinâmica de poder que deu origem às revoluções dos séculos XVII e XVIII, inaugurando-se a tradição constitucionalista moderna. Após isso, passa-se à análise de alguns princípios que foram sendo acumulados pela tradição constitucionalista, nos séculos de XVIII a XX, com atenção aos contextos históricos, período em que ocorrem profundas alterações nas funções do Estado.

No segundo momento do artigo, se faz uma reflexão sobre a realidade da democracia pós-autoritária brasileira, na qual ainda não existem instituições democráticas sólidas e a manifestação da ideia de normatividade constitucional, uma vez que a Constituição é relativizada em vários aspectos em favor do poder político e do poder econômico. Nesse contexto, ainda, se desvela como se dá a sobreposição de poderes à Constituição, 
trazendo-se à análise a questão da atuação dos meios de comunicação no país e de seu oligopólio.

Adota-se, como técnica de pesquisa, a revisão bibliográfica, e busca-se o desenvolvimento metodológico do trabalho a partir da construção de um quadro referencial teórico coerente e integrado à historicidade.

\section{UM BREVE RETROSPECTO SOBRE O CONCEITO DE CONSTITUCIONALISMO}

A ideia de Constituição, que ainda no século XXI se mantém viva, deita suas raízes nos acontecimentos que se desenrolaram durante a transição do período histórico do medievo para a primeira modernidade europeia, especialmente no que se deu na sequência nos séculos XVII e XVIII. Como se sabe, a primeira versão do Estado Moderno surgiu com o ocaso do período do medievo e, nesse momento inicial, ele aparece como Estado Absolutista, com o intuito de criar soluções para o cenário de desordem que se apresentava a partir da instabilidade gerada pelas guerras religiosas e desintegração do feudalismo (LIMA, 2015, p. 29). O fenômeno do absolutismo foi o caminho necessário para a imposição de uma ordem una que se sobrepusesse a todas as outras formas de poder, já que as outras ordens fragmentadas eram uma característica da ordem política medieval.

Não havia efetivamente uma dimensão política como se concebe hoje. O que se tinha era a imposição do poder absoluto do soberano para a sobreposição de outros poderes que se apresentavam na realidade. A "política", nesse sentido, era o soberano.

Para os limites do presente trabalho, não se buscará delinear o absolutismo em suas diferentes manifestações, o que se pretende é apenas a colocação do quadro de desintegração do feudalismo e da necessária imposição de um poder político central e absoluto que desse conta de trazer estabilidade à realidade caótica que vinha se apresentando com constância ${ }^{1}$. Diante da imensa necessidade de imposição absoluta do poder político, a força foi algo sempre presente pois, de forma contrária, estar-se-ia sempre às voltas com a possibilidade de nova fragmentação - , gerando um fenômeno que se apresentou, com o decorrer do tempo, na forma de um poder ilimitado, em que o governante cometia arbitrariedades sem que pudesse ser controlado de nenhuma maneira.

Os levantes e movimentos revolucionários que surgem nos séculos XVII e XVIII são iniciados justamente por conta do descontentamento dos súditos com a atuação dos absolutos soberanos, com o exercício irresponsável do poder político e com o beneficiamento, pelo governante, de poucos grupos sociais em detrimento de outros, que eram excluídos das esferas de benesses do poder. Os três movimentos que deram início a uma nova forma de se enxergar e de se relacionar com o poder foram aqueles que ocorreram na Inglaterra do século XVII, culminando na Revolução Gloriosa; nos Estados Unidos da América (até então "Treze Colônias") do século XVIII, levando à conquista de sua independência da metrópole inglesa; e na França do século XVIII, que conduziu à Revolução Francesa, tida como o emblemático momento ruptural de efetivo início da modernidade.

Esses três momentos históricos, que sofreram grande influência do caldo de cultura produzido pelos teóricos do Contratualismo ${ }^{2}$

\footnotetext{
Nessa perspectiva, a título de exemplo, menciona-se a experiência francesa como uma legítima manifestação do Estado Absolutista, em que o soberano concentrava em si o exercício de todas as faculdades do poder - algo que se repetiu, também, na Inglaterra e em outras partes da Europa, com outras roupagens e personagens, mas também com ausência de limites ao poder do soberano.

${ }^{2}$ Escola de pensamento que se desenvolveu nos séculos XVII e XVIII, especialmente na Inglaterra e na França, que tinha por objetivo a descrição das condições que levaram a humanidade à transição de um momento présocietário ("estado de natureza") ao estabelecimento da
} 
(como os ingleses Thomas Hobbes e John Locke; o francês Jean-Jacques Rousseau; entre outros) e do Iluminismo, na sequência de seus desenvolvimentos ficaram conhecidos como revoluções liberais, que deram início às três matrizes constitucionais ${ }^{3}$ clássicas: francesa, inglesa e estadunidense ${ }^{4}$.

Importante salientar que o constitucionalismo moderno nasce com um objetivo muito bem delineado: combater a tirania e buscar uma forma de contenção dos arbítrios do soberano, de modo que esse ficasse submetido àquilo que se inscrevia nas Constituições. Aqui se deu um passo adiante, pois:

a questão enfrentada durante a transição para a [primeira] modernidade não estava na problemática da limitação do exercício do poder político, mas na necessidade de imposição do poder político para a superação da instabilidade social causada pela decadência do feudalismo (LIMA, 2015, p. 30).

Uma vez que o Absolutismo, com o passar do tempo, se mostrou altamente pernicioso para a grande maioria dos viventes sob seu domínio, viu-se florescer o descontentamento com essa forma de dominação, de modo que, com os mencionados movimentos revolucionários, foi imposto $\mathrm{o}$ declínio do modelo de Estado Absolutista,

sociedade civil, através da elaboração de um "contrato social".

${ }^{3}$ E nesse ponto são reveladas as grandes influências desses movimentos, pois: “A reivindicação de uma Constituição embasava-se exatamente na tese de que o contrato social encontra sua explicitação na Constituição" (MORAIS; STRECK, 2014, p. 55).

${ }^{4}$ De se consignar que há autores, ligados à Teoria Crítica dos Direitos Humanos (por todos, Cf. David Sánchez Rubio), que lembram que uma das revoluções constitucionais do referido período também foi a Revolução Haitiana: a primeira em que ex-escravos, de ascendência africana, tomaram o poder e se deram uma Constituição - mas esse fato histórico é deixado de lado, posto que não interessa aos usos da burguesia e seu projeto ao poder. dando-se sequência à ascensão da segunda versão do Estado Moderno: o Estado Liberal.

Essa nova manifestação estatal foi acompanhada, como já mencionado, de um movimento de criação de constituições. Ainda que se possa defender que já, antes da modernidade, houve alguma manifestação da ideia de limitação do poder, com documentos jurídicos que garantiam o exercício de alguns direitos (como, por exemplo, a "Magna Carta do Rei João Sem Terra" ${ }^{5}$ ), o que se busca tratar aqui é o sentido do Constitucionalismo Moderno (em sua etapa germinal, "Constitucionalismo Liberal"), surgido nesse período posterior às revoluções liberais.

Com essa viragem, o que se deu foi o surgimento de constituições que tinham por escopo a limitação do poder - em todas as suas variáveis, mas especialmente o poder político, que outrora havia sido imposto com força despótica -, trazendo, especialmente com base na doutrina de Montesquieu, a necessidade de sua repartição, para que, sendo executado por órgãos com competências específicas diversas, não voltasse a se absolutizar; iniciando também a garantia de uma ideia de previsibilidade para os cidadãos (e não mais súditos, como antes).

Para limitar os excessos cometidos pelo poder político, os movimentos revolucionários perceberam que as funções legislativa, executiva e judicial não poderiam continuar concentradas numa única pessoa ou instituição - como ocorria nos tempos do absolutismo, quando os monarcas acumulavam simultaneamente as atividades do gubernaculum e da jurisdictio. A partir do constitucionalismo, a limitação do poder

\footnotetext{
5 Pode se dizer que o direito constitucional "deita suas raízes na própria idade média quando pensamos no constitucionalismo inglês, por exemplo. Ilustrativa nesse sentido é a Carta Magna do Rei João Sem Terra de 1215, que apesar de possuir caráter estritamente conservador, já determinava uma limitação ao poder real absoluto e trazia os parâmetros mínimos para se dar início à consolidação do princípio constitucional do devido processo legal”. (ABBOUD; CÁRNIO; OLIVEIRA, 2015, p. 275).
} 
político teve que passar inevitavelmente por uma maior separação entre os poderes do Estado (Legislativo, Judiciário e Executivo) (LIMA, 2015, p. 38).

É necessário mencionar, ainda, com o amparo de Mateucci (1998, p. 27-28), que ao se analisar o Constitucionalismo Moderno, há que se fazer uma importante observação: não existe apenas um constitucionalismo; o que há são vários constitucionalismos, cada um seguindo as condicionantes históricas de cada local onde se deu a adoção de uma determinada Constituição. Nessa perspectiva, a intenção de se tratar o movimento constitucionalista é a de se fazer uma análise dos princípios gerais que se formaram e se tornaram "patrimônio comum" entre os tipos de constitucionalismo existentes.

Com essa advertência, torna-se claro que a limitação do poder político é um princípio fundamental da história constitucional, originado na fase inicial do constitucionalismo liberal, e compartilhado por todas as experiências modernas do gênero. Logo, verifica-se que, com o movimento de se limitar o poder político através de uma Constituição - baseada na vontade geral ou na tradição histórica de um povo -, colocando-se restrições claras à política através da obediência à lei, conferiu-se um importante espaço para os prolegômenos de uma regulação jurídica das relações humanas ${ }^{6}$.

Nessa etapa inicial, no Estado Liberal, o Direito, que antes estava subjugado pela política, adquiriu a função de ordenação (OLIVEIRA, 2008, p. 72), momento em que, na esteira da limitação do poder, se tem, por meio da Constituição, a organização políticoadministrativa do Estado (com divisão de poderes) e a garantia de direitos civis e políticos aos cidadãos.

\footnotetext{
${ }^{6}$ Estão aí os primórdios daquilo que se chama "Estado de Direito", o Estado que não mais está submetido à vontade política de quem quer que o domine, mas se submete à Constituição e à legalidade.
}

Com os desdobramentos e crises do modelo liberal de governança e diante das alterações das condições políticas e sociais durante todo o século XIX (e com o fortalecimento e crescimento do ideário crítico socialista, especialmente representado pelos escritos de Karl Marx e Friedrich Engels), em linhas gerais o Estado Liberal-burguês passa a ter grandes dilemas sem solução: diante da modificação - com a Revolução Industrial - do modo de produção, surge uma nova classe de trabalhadores - que antes era dona de manufaturas e trabalhava para si e, nessa sucessão de mudanças, passa a ser empregada dos grandes proprietários de indústrias, receber baixos salários e trabalhar por horas sem nenhum descanso -; há uma grande ampliação das populações urbanas, com o crescimento desordenado das cidades, ausência de saneamento básico, saúde e infraestrutura urbana inadequada; enfim, o mundo já não era mais aquele para o qual o Estado Liberal era suficiente.

Diante das insuficiências das respostas liberais para os novos problemas que se apresentavam nesse cenário, viu-se surgir grande necessidade de modificação na forma de atuação política, o que se poderia comparar com o que ocorreu na primeira modernidade europeia: instaurou-se o absolutismo para a concentração do poder político contra a fragmentação que ocorrera com o feudalismo, e isso passou a ser o problema que teve que ser superado pela segunda transição, ao Estado Liberal; agora, verifica-se que o modelo de Estado que se iniciou com as revoluções liberais - aquele que tem seu poder demasiadamente limitado (Estado minimalista) e tem o dever de respeitar as liberdades individuais, absenteísta em sua origem - já não tem mais as respostas para todos os novos cenários que se apresentam, uma vez que seria necessária a intervenção do Estado para a solução de problemas específicos, que escapam 
à esfera privada dos indivíduos e passam à esfera pública.

Da série de acontecimentos que se deram especialmente na segunda metade do século XIX - lutas por direitos trabalhistas, direitos políticos, melhorias nas condições de vida urbanas -, viu-se o surgimento de um novo modelo de Estado (nos fins do século XIX e princípios do $\mathrm{XX}$ ), não mais absenteísta e mínimo, mas que tinha por dever a intervenção no domínio econômico e social, de modo a garantir condições mínimas de bem-viver a seus cidadãos e a redução de desigualdades: o Estado Social - e nele o Direito passa a ter uma função promovedora (OLIVEIRA, 2008, p. 72), com uma nova etapa do constitucionalismo, em que há previsão, na Constituição, de direitos sociais e econômicos; o Estado não mais se abstém, mas promove direitos a seus cidadãos ${ }^{7}$.

Alguns exemplos de Constituição Social que adotaram a promoção de direitos sociais e econômicos foram a Constituição Mexicana de 1917 e a Constituição de Weimar de 1919. Entretanto, essa fase inicial de desenvolvimento do Estado Social contrastou, na Europa, com o surgimento (na década de 30 do século XX) do nazi-fascismo e dos Estados Totalitários, nos quais não havia propriamente uma dimensão do Direito - senão aquele Direito que era colocado e ditado pelo supremo líder da nação. Nesse Estado de Exceção ${ }^{8}$, todo o acúmulo histórico de

\footnotetext{
7 Como já se mencionou, os princípios do constitucionalismo se tornam um patrimônio comum, e isso se comunica, através da história, em todas as nações que adotaram constituições. Assim, não se trata de imaginar que o constitucionalismo liberal teria sido abandonado e esquecido, especialmente em sua dimensão de limitação dos arbítrios do poder, mas que o constitucionalismo social, que agora surge, continua a ter o dever de limitação do poder, com a característica complementar de garantir direitos sociais e econômicos aos cidadãos.

8 "O totalitarismo moderno pode ser definido, nesse sentido, como a instauração, por meio do estado de exceção, de uma guerra civil legal que permite a eliminação física não só dos adversários políticos, mas também de categorias inteiras de cidadãos que, por
}

princípios e de conquistas das lutas sociais e do constitucionalismo se viu ofuscado, totalmente afastado das possibilidades democráticas.

Esse período culminou na Segunda Guerra Mundial e ficou conhecido pelas grandes atrocidades cometidas, nunca imaginadas como algo possível de serem praticadas por seres humanos numa escala de racionalidade industrial: grandes genocídios; torturas e perseguições constantes de inimigos políticos; militarização de toda a burocracia estatal; a instituição de um Direito-excepcional, que dava ares de legitimidade a tudo que se praticou; a demonstração do potencial destrutivo de armamentos atômicos.

Com o final da guerra, em 1945, reinstaura-se o fluxo histórico que havia sido interrompido, com a necessidade de superação do cenário totalitário e reconstrução das perspectivas jurídico-democráticas e sociais. A propósito desse período, Mário Losano (2010, p. 185 e ss.), ao se referir às características do Direito que passa a ser produzido, diz ser um "Direito pós-bélico" ou "Direito pós-Auschwitz" - justamente com o intento de demonstrar a necessidade de superação dos acontecimentos passados e de reflexão sobre um Direito que não possa ser instrumentalizado pela política.

Nessa fase nasce o que, na doutrina jurídica, convencionou-se chamar de Estado Democrático de Direito, que é o fenômeno por meio do qual se busca reforçar a autonomia do Direito frente a seus predadores externos (Cf. STRECK, 2013), como a política, a economia e a moral:

Partindo de uma análise substancialista, no Estado Democrático de Direito é agregada ao Direito uma função transformadora da realidade social, representada pelo resgate das promessas da modernidade, que é indispensável para o desenvolvimento racional de um país como o Brasil que sucumbiu ao

qualquer razão, pareçam não integráveis ao sistema politico" (AGAMBEN, 2004, p. 13). 
Estado Social e nem mesmo o Estado Liberal formal-burguês existiu de fato em seus domínios (OLIVEIRA; SILVEIRA, 2013, p. 19).

Assim, diante do patrimônio comum que já havia se acumulado pelas tradições anteriores do constitucionalismo (no Estado Liberal de Direito e no Estado Social de Direito), nessa nova etapa ainda se mantém o intento de limitação do poder e de promoção de direitos sociais, mas os riscos que a democracia corre foram demonstrados pela ofensiva totalitária, fazendo com que o Direito (e, por óbvio, o constitucionalismo) tenha a necessidade de manter um alto grau de autonomia e de garantir a efetividade dos direitos humanos fundamentais e da dignidade humana.

\section{A DEMOCRACIA PÓS-AUTORITÁRIA BRASILEIRA E O APEQUENAMENTO DA IDEIA DE NORMATIVIDADE CONSTITUCIONAL}

Colocadas em abstrato algumas das características do constitucionalismo, cumpre-se passar a uma análise específica sobre o impacto dessa tradição e a forma como foram recebidos seus princípios (patrimônio comum), especialmente no tocante à ideia de transformação da realidade no caso da democracia brasileira. Para tanto, faz-se um recorte a partir do período em que a República brasileira constituiu-se em Estado Democrático de Direito, ou seja, com a Constituição da República Federativa do Brasil de 1988. É importante essa diferenciação diante do passado de autoritarismo vivido pelo país, não apenas com a ditadura militar que se implantou de 1964 até as vésperas da nova Constituição, mas de todo o passado histórico, que não se pode dizer democrático, posto que houve uma sucessão de golpes de Estado, de violência e de períodos de suspensão da legalidade.
Esse período, iniciado com a Constituição de 1988 - a "Constituição Cidadã" -, é alvissareiro, já que, pela primeira vez se viu a possibilidade de consolidação democrática. A instauração de um "Estado Democrático de Direito" por uma Constituição que teve sua elaboração em período de amplo debate com a sociedade e diversos movimentos sociais, tem, ainda que formalmente, uma grande mensagem a passar: diante da memória e da história serão corrigidos e superados os problemas do passado, de modo que não se erre como nos tempos anteriores.

Guillermo O'Donnell (1991), que em muitos de seus trabalhos se debruçou sobre o estudo das democracias pós-autoritárias - novas democracias, especialmente as da América Latina, que passaram por longos períodos de autoritarismo e de suspensão da legalidade democrática -, sugere que a transição de um governo autoritário para um democrático é muito mais complexa e demorada que a mera instituição de um marco inicial democrático. Haveria uma primeira mudança, a formalização da abertura democrática, que deveria ser seguida de uma segunda transição, mais profunda, "espera-se que essa segunda transição seja de um governo democraticamente eleito para um regime democrático ou, o que é equivalente, para uma democracia institucionalizada consolidada" (O’DONNELL, 1991, p. 26).

Ele também sugere (O’DONNELL, 1991, p. 25), nessa análise sobre o contexto político nos países latino-americanos (e ele faz referência expressa ao caso brasileiro), o surgimento do que chamou de "um 'novo animal', um subtipo das democracias existentes [...]", a democracia delegativa - na qual, além de outras peculiaridades levantadas pelo autor (que conduzem ao esvaziamento da política e da cidadania), diante das crises social e econômica e da ausência de instituições democráticas sólidas, se confere um poder praticamente ilimitado ao 
presidente da República, delegando a ele todas as expectativas do destino da nação, tornando-o o "grande escolhido", aquele que atuará, com sua equipe de "sábios", com pacotes de reformas, rumo ao sucesso e à salvação - e, para que se possa alcançar "tão nobre objetivo", tudo é aceitável.

Uma democracia não institucionalizada é caracterizada pelo escopo restrito (fundamentalmente de base classista), pela fraqueza e pela baixa densidade de suas instituições. Outras instituições, não formalizadas mas fortemente atuantes especialmente $\quad \mathrm{o} \quad$ clientelismo, $\quad \mathrm{o}$ patrimonialismo e, certamente, a corrupção tomam o lugar daquelas, juntamente com vários padrões de acesso direto e altamente desagregado ao processo de tomada de decisão e implementação de políticas públicas (O’DONNELL, 1991, p. 30).

O autor fez essas observações no início da última década do século XX, quando muitas democracias estavam a se inventar, superando suas chagas históricas e buscando a abertura para a pluralidade e a instituição de mudanças com base na tradição constitucional. Entretanto, apesar da distância temporal, pode ser dito, com clareza, que a democracia brasileira, a despeito de todas as conquistas do Estado Democrático de Direito e de quase trinta anos de Constituição, ainda permanece presa nesse interregno da transição da "primeira democracia" para o "regime democrático"; não apenas pela grande desigualdade social e exclusão de determinados grupos sociais das esferas do poder, mas pela própria forma como se dão os processos de tomada de decisões públicas, sem nenhuma responsabilidade política (accountability) dos agentes.

O problema que se apresenta, de imediato, é o de que a Constituição se vê, nesse cenário, constantemente atacada e predada por

uma realpolitik ${ }^{9}$ e por juízos econômicos e morais. As conquistas do constitucionalismo moderno fizeram com que o Direito ganhasse um grau de autonomia que o manteria à salvo das repentinas mudanças do cenário político e econômico, de modo que fossem conservados os direitos fundamentais dos cidadãos, o núcleo democrático e a cidadania; entretanto, com a não-superação do autoritarismo histórico, que subjaz às relações de poder presentes no Brasil, há um constante esvaziamento do caráter transformador do Direito, fazendo com que as questões jurídicas fiquem sempre adstritas à vontade dos donos do poder (FAORO, 2012), que são infalíveis na colocação de seu projeto de dominação, havendo uma colossal blindagem da esfera política, que garante que as questões públicas sejam decididas de modo alheio aos interesses e necessidades da população (NOBRE, 2014), em benefício apenas do estamento político, que atua sempre para si.

O funcionamento autoritário do Estado brasileiro, que, durante a maior parte da história republicana, procurou se impor como demiurgo da sociedade - na tentativa de sufocar a atuação dos movimentos sociais -, não foi eliminada totalmente após a redemocratização. Essa situação é responsável pelo déficit de cidadania ainda presente na sociedade brasileira, que, no caso, mesmo após a redemocratização e a promulgação da Constituição de 1988, ainda encontra dificuldades para fazer com que suas reivindicações sejam ouvidas pelas estruturas de poder do Estado. O sistema político se encontra blindado em relação aos movimentos que ocorrem nas ruas e contribui para distanciar cada vez mais os representantes políticos das pessoas comuns. Essa situação foi observada por Marcos Nobre em seu livro "Imobilismo em movimento", ao utilizar um novo conceito para compreender o modus operandi do sistema político brasileiro. Segundo ele, após a

\footnotetext{
${ }^{9}$ Que não se restringe à atuação presidencial.
} 
redemocratização, o sistema passou a operar de forma autônoma em relação à sociedade, buscando arrefecer os conflitos sociais e as disputas políticas que ocorrem naturalmente numa democracia. Esse fenômeno foi denominado, por Nobre, como "peemedebismo" (NOBRE, 2013, p. 11) ${ }^{10}$.

Nesse ambiente dominado pelo "peemedebismo", as pautas reivindicatórias de setores marginalizados da sociedade brasileira não encontram espaço no Parlamento. São sufocadas prematuramente pelos grupos de pressão que alcançam maioria entre os parlamentares e impedem que as minorias consigam debater suas posições. Ou seja, a redemocratização não foi capaz de abrir por completo as instituições políticas brasileiras, pois manteve um grau significativo de blindagem do sistema político em relação à sociedade, dificultando a realização da ideia de governo responsável.

Desse modo, é possível afirmar que a democracia brasileira continua pouco democrática no funcionamento de seu sistema representativo. Segundo Octavio Ianni (2004, p. 120-121):

Modernizam-se a economia e o aparelho estatal. Simultaneamente, os problemas sociais e as conquistas políticas revelam-se defasados. [...]. A mesma nação industrializada, moderna, conta com situações sociais, políticas e culturais desencontradas".

Um desencontro intencional que, ainda segundo as palavras de Ianni, pertence ao próprio modelo de modernização capitalista seguido pelo Brasil, que contribuiu para cristalizar o modo autoritário de lidar com os conflitos sociais.

\footnotetext{
10 Apesar de esse conceito fazer referência ao PMDB, Nobre destaca que o fenômeno do peemedebismo não se reduz somente a esta organização partidária, mas é utilizado em sua obra para explicar o funcionamento do sistema político brasileiro.
}

Esses entraves da democracia brasileira devem-se à não superação daquele imaginário que Konrad Hesse (1991) buscou enfrentar por meio de sua ideia de "Constituição normativa". Em sua obra, publicada pela primeira vez em 1959 (portanto, já no contexto do Direito do segundo pós-guerra), o autor se contrapõe à postura teórica de Ferdinand Lassalle, que defendia que a Constituição era apenas um documento formal que descrevia fielmente as forças que estavam presentes na realidade - se assim não fosse, no embate entre a Constituição real e a Constituição jurídica, essa última deveria sempre sucumbir, em favor dos fatores reais de poder que conformam a realidade social e política de determinada nação -; de seu lado, Hesse defendeu que a Constituição não seria apenas um documento descritivo dessas forças que se encontram em disputa em determinada realidade, mas seria dotada de "normatividade", ou seja, enquanto pré-compromisso firmado pelos cidadãos, a Constituição emanaria sua normatividade para toda a tessitura jurídicopolítica, sendo capaz de promover modificações na realidade que se apresenta por meio do comprometimento daqueles responsáveis por sua execução.

Embora a Constituição não possa, por si só, realizar nada, ela pode impor tarefas. A Constituição transforma-se em força ativa se essas tarefas forem efetivamente realizadas, se existir a disposição de orientar a própria conduta segundo a ordem nela estabelecida, se, a despeito de todos os questionamentos e reservas provenientes dos juízos de conveniência, se puder identificar a vontade de concretizar essa ordem. Concluindo, pode-se afirmar que a Constituição converter-se-á em força ativa se fizerem-se presentes, na consciência geral - particularmente, na consciência dos principais responsáveis pela ordem constitucional - não só a vontade de poder (Wille zur Macht), mas também a vontade de Constituição (Wille zur Verfassung) (HESSE, 1991, p. 20). 
Isso posto, pode ser verificado que no Brasil ainda pouco se manifesta essa ideia de normatividade constitucional. Ainda que muitos possam defendê-la, no campo teórico, muito falta desse comprometimento ético com o cumprimento daquilo que se inscreveu no pacto civilizatório de 1988 - pela ausência, por parte dos cidadãos, de uma "cultura constitucional"; pela inexistência de instituições suficientemente democráticas; pela continuidade da prevalência dos fatores reais de poder no momento em que são decididas as questões da República.

$\mathrm{O}$ que se pode mencionar, como um exemplo (dentre muitos outros existentes) concreto para a compreensão desse cenário de ausência de concretização do compromisso constitucional no Brasil, é o caso emblemático da comunicação social. No "Capítulo V: Da Comunicação Social", do "Título VIII: Da Ordem Social”, da Constituição de 1988, para além da serem abordadas outras questões, estão disposições que estabelecem princípios democráticos para a atuação dos meios de comunicação - prescreve-se, para os conteúdos da radiodifusão de sons e de sons e imagens, a prevalência de programações com "finalidades educativas, artísticas, culturais e informativas" (BRASIL, Artigo 221, inciso I); a "promoção da cultura nacional e regional e estímulo à produção independente que objetive sua divulgação" (BRASIL, Artigo 221, inciso II); a "regionalização da produção cultural, artística e jornalística, conforme percentuais estabelecidos em lei” (BRASIL, Artigo 221, inciso III); e o "respeito aos valores éticos e sociais da pessoa e da família" (BRASIL, Artigo 221, inciso IV).

Muitas críticas podem ser realizadas no que concerne à atuação da mídia, justamente pela forma como são instrumentalizados os dispositivos constitucionais, de modo a dar prevalência a interesses corporativos e a uma postura mercadológica no momento da veiculação de programações, o que faz com que sejam esvaziadas as determinações constitucionais em favor dos fatores reais de poder que estão envolvidos no mercado da informação.

Também, diante do disposto no Artigo 220, parágrafo $5^{\circ}$, da Constituição de 1988 (BRASIL) - que proscreve que os meios de comunicação sejam objeto de monopólio ou oligopólio -, quando se analisa a situação proprietária da mídia no país, é exatamente o oposto que se verifica, já que poucos grupos empresariais ${ }^{11}$ são detentores dos maiores veículos de mídia do país - em nítido oligopólio -, entre canais de televisão, rádios, revistas, jornais, sites, editoras.

É interessante a crítica à atuação da imprensa feita por Emiliano José (2010), em sua obra "Jornalismo de Campanha e a Constituição de 1988”, na qual analisa a interferência da atuação midiática nas reformas realizadas na Constituição Federal, no período de 1988 a 1998, concluindo que os meios de comunicação tiveram papel central na defesa e implementação, através de um "jornalismo de campanha", de uma agenda neoliberal no Brasil, sendo parciais na veiculação de informações do campo político, defendendo grandes mudanças constitucionais sem cumprir seu dever de propiciar um debate público democrático. Lembrando-se que o inconstitucional desvio na conduta dos meios de comunicação se deu justamente com o interesse de promover alterações na Constituição (e, nesse caso, o oligopólio informativo volta ao debate, já que a concentração proprietária da mídia se mostra como forte aliada à construção de um discurso uníssono, sem pluralidade, especialmente no Brasil, onde as divergências entre variadas empresas da comunicação se apresentam apenas como divergências mercadológicas e de roupagens, sem que se consubstanciem em diversificação das linhas

${ }^{11}$ Como Globo, SBT, Bandeirantes, Record, Abril, Folha de São Paulo, O Estadão. 
editoriais, o que torna a concentração informativa mais perniciosa ainda).

Ao se verificar a prevalência de interesses privados em detrimento do que se estabelece na Constituição Federal, fica nítida a situação de predação do Direito e da normatividade constitucional pelos fatores reais de poder: ignora-se o pré-compromisso constitucional para que seja dada prevalência aos interesses particulares que estão em disputa nos cenários político e, especialmente, econômico.

Dessa forma, é possível afirmar que o que se construiu, no Brasil, em torno da ideia de Constituição, ainda não foi suficiente para a superação do quadro de tradições autoritárias que se impuseram sobre o país em seu passado. Não é possível verificar, com total clareza, a plena implementação dos mecanismos de contenção do poder e de controle democrático da esfera pública; sendo nítida, no entanto, a relativização da Constituição Federal frente às paixões do espectro político e à globalização econômica (que se amplia cada vez mais). Por isso, faz-se necessário o resgate da ideia de Constituição normativa e de autonomia do Direito e do précompromisso civilizatório, de modo que se possa completar a segunda transição política, como defende O’Donnell (1991, p. 26), para um regime democrático - em que haja instituições republicanas sólidas e respeito aos preceitos da Constituição Federal.

\section{CONCLUSÃO}

Buscou-se, no presente trabalho, um breve revolvimento das camadas de sentido que se sobrepõem no conceito moderno de constitucionalismo, de maneira a se dar visibilidade às questões contextuais que sempre estiveram presentes no desenvolvimento dessa tradição - e que devem ser desveladas para uma correta compreensão de todo o sentido e extensão desse fenômeno.
Quando o cenário que se apresentava era o de necessidade de superação da concentração absoluta do poder político originada na transição do medievo para a primeira modernidade europeia -, o constitucionalismo, em sua etapa germinal, se mostrou como o caminho adequado para limitação do poder do Estado (e superação do absolutismo), conferindo uma forma de proteção aos direitos individuais e possibilitando o surgimento da esfera de direitos civis e políticos.

Com a sucessão de acontecimentos que se inicia nos últimos anos do século XVIII e se expande durante todo o século XIX e início do século XX (como, por exemplo, a Revolução Industrial), percebe-se a necessidade de uma adequação dos princípios clássicos do primeiro constitucionalismo (que garantiram um modelo de Estado controlado e absenteísta), possibilitando novas respostas aos questionamentos que surgiam nos inéditos cenários que se apresentavam - por exemplo, o surgimento de direitos sociais e de um Estado mais atuante na promoção desses direitos.

Essas ressignificações do constitucionalismo continuam a acontecer cotidianamente, e o que se apresenta na atualidade do século XXI é a configuração de sua nova etapa, que se iniciou no final da primeira metade do século $\mathrm{XX}$ - após o final do período excepcional do Totalitarismo -, com um sólido compromisso, ainda, com a limitação do Estado e com a promoção de melhorias nas condições sociais, mas sendo complementado por princípios para a garantia da dignidade humana, da igualdade e da efetivação dos direitos humanos fundamentais.

A Constituição de 1988 se insere nessa tradição constitucional surgida após a Segunda Guerra Mundial, entretanto, conforme se argumentou com amparo em Guillermo O'Donnell (1991), a realidade brasileira ainda não passou pela experiência de um regime 
democrático - com instituições democráticas e republicanas sólidas -, encontrando-se, ainda, em um estágio de tentativa de superação de seu passado de modernização autoritária.

Apesar de grandes conquistas do período democrático, ainda pouco se manifesta o respeito à noção de normatividade constitucional, uma vez que, em muitos casos, a Constituição se vê esvaziada pela prevalência, no espaço público, de forças políticas e econômicas, em detrimento de sua força normativa - como é o caso, trazido para exemplificação, da comunicação social no país, que é exercida, muitas vezes, assumindo práticas inconstitucionais (especialmente no que tange ao oligopólio dos meios de comunicação, gerido por uma verdadeira "oligarquia da informação").

As condições de possibilidade para a superação desses problemas passam, necessariamente, pelo resgate da noção de normatividade constitucional, que remonta à tradição constitucionalista, trazendo maiores possibilidades e menores riscos para a construção da esfera pública - que deve se construir a partir de um forte comprometimento com a consolidação das instituições democráticas e com o "patrimônio comum" de princípios constitucionais acumulados durante a história moderna.

\section{REFERÊNCIAS}

ABBOUD, Georges; CARNIO, Henrique Garbellini; OLIVEIRA, Rafael Tomaz de. Introdução à Teoria e à Filosofia do Direito. 3. ed. rev., atual. e ampl. São Paulo: Revista dos Tribunais, 2015.

AGAMBEN, Giorgio. Estado de Exceção. Tradução de Iraci D. Poleti. São Paulo: Boitempo, 2004.

BRASIL. Constituição da República Federativa do Brasil, de 05 de Outubro de 1988. Disponível em: <http://www.planalto.gov.br/ccivil_03/Constituicao/Constituicao.htm>. Acesso em: 25 jan. 2018.

FAORO, Raymundo. Os donos do poder. Formação do patronato político brasileiro. 5. ed., São Paulo: Globo, 2012.

HESSE, Konrad. A Força Normativa da Constituição. Porto Alegre: Sergio Antonio Fabris Editor, 1991.

JOSÉ, Emiliano. Jornalismo de Campanha e a Constituição de 1988. Salvador: EDUFBA; Assembleia Legislativa da Bahia, 2010.

LIMA, Danilo Pereira. Constituição e Poder: limites da Política no Estado de Direito. Porto Alegre: Livraria do Advogado, 2015.

LOSANO, Mario Giuseppe. Sistema e Estrutura no Direito. São Paulo: Martins Fontes, 2010. v. I.

MATEUCCI, Nicola. Organización del Poder y Libertad: historia del constitucionalismo moderno. Madrid: Trotta,1998.

MORAIS, José Luis Bolzan de; STRECK, Lenio Luiz. Ciência Política e Teoria do Estado. 8. ed. rev. e ampl., Porto Alegre: Livraria do Advogado, 2014. 
NOBRE, Marcos. Imobilismo em Movimento. São Paulo: Cia. das Letras, 2014.

O'DONNELL, Guillermo. Democracia Delegativa? Novos Estudos, São Paulo, n. 31, p. 25-40, 1991.

OLIVEIRA, Rafael Tomaz de. Decisão judicial e o conceito de princípio: a hermenêutica e a (in)determinação do Direito. Porto Alegre: Livraria do Advogado, 2008.

; SILVEIRA, Ricardo dos Reis. A Jurisdição Constitucional Para Além do Mito do Legislador Negativo: concreção do projeto constitucional e cidadania no estado democrático de direito. Revista Paradigma, Ribeirão Preto, n. 22, p. 2-26, 2013.

STRECK, Lenio Luiz. Jurisdição constitucional e decisão jurídica. 3. ed., São Paulo: Revista dos Tribunais, 2013.

Recebido em: 09/06/2018

Aceito em: 29/01/2019 
